\title{
ARDS: challenges in patient care and frontiers in research
}

\author{
Lieuwe D. Bos ${ }^{1,2}$, Ignacio Martin-Loeches ${ }^{3}$ and Marcus J. Schultz ${ }^{1,4}$ \\ Number 1 in the Series "Highlights in acute respiratory failure" \\ Edited by Leo Heunks and Raffaele Scala
}

Affiliations: ${ }^{1}$ Dept of Intensive Care and Laboratory of Experimental Intensive Care and Anesthesiology (LEICA), Academic Medical Center, Amsterdam, The Netherlands. ${ }^{2}$ Respiratory Medicine, Academic Medical Center, Amsterdam, The Netherlands. ${ }^{3}$ Dept of Intensive Care, St James's Hospital, Dublin, Ireland. ${ }^{4}$ Mahidol Oxford Tropical Medicine Research Unit (MORU), Faculty of Tropical Medicine, Mahidol University, Bangkok, Thailand.

Correspondence: Lieuwe D. Bos, Academic Medical Center, Amsterdam, Room M0-127, 1105 AZ Amsterdam, The Netherlands. E-mail: l.d.bosdamc.uva.nl

@ERSpublications

Treatment of ARDS is mainly through the prevention of ventilation-induced lung injury http://ow.ly/DeJC30hGWfi

Cite this article as: Bos LD, Martin-Loeches I, Schultz MJ. ARDS: challenges in patient care and frontiers in research. Eur Respir Rev 2018; 27: 170107 [https://doi.org/10.1183/16000617.0107-2017].

ABSTRACT This review discusses the clinical challenges associated with ventilatory support and pharmacological interventions in patients with acute respiratory distress syndrome (ARDS). In addition, it discusses current scientific challenges facing researchers when planning and performing trials of ventilatory support or pharmacological interventions in these patients.

Noninvasive mechanical ventilation is used in some patients with ARDS. When intubated and mechanically ventilated, ARDS patients should be ventilated with low tidal volumes. A plateau pressure $<30 \mathrm{cmH}_{2} \mathrm{O}$ is recommended in all patients. It is suggested that a plateau pressure $<15 \mathrm{cmH}_{2} \mathrm{O}$ should be considered safe. Patient with moderate and severe ARDS should receive higher levels of positive endexpiratory pressure (PEEP). Rescue therapies include prone position and neuromuscular blocking agents. Extracorporeal support for decapneisation and oxygenation should only be considered when lungprotective ventilation is no longer possible, or in cases of refractory hypoxaemia, respectively. Tracheotomy is only recommended when prolonged mechanical ventilation is expected.

Of all tested pharmacological interventions for ARDS, only treatment with steroids is considered to have benefit.

Proper identification of phenotypes, known to respond differently to specific interventions, is increasingly considered important for clinical trials of interventions for ARDS. Such phenotypes could be defined based on clinical parameters, such as the arterial oxygen tension/inspiratory oxygen fraction ratio, but biological marker profiles could be more promising.

Received: Sept 202017 | Accepted after revision: Dec 132017

Support statement: Funding was received from the European Respiratory Society (short-term fellowship) and Longfonds ( junior investigator grant). Funding information for this article has been deposited with the Crossref Funder Registry.

Conflict of interest: Disclosures can be found alongside this article at err.ersjournals.com

Provenance: Commissioned article, peer reviewed.

Copyright OERS 2018. ERR articles are open access and distributed under the terms of the Creative Commons Attribution Non-Commercial Licence 4.0. 


\section{Introduction}

Optimal care for patients with acute respiratory distress syndrome (ARDS) has changed noticeably over recent years. This holds particularly true for ventilatory support, essential in almost all ARDS patients, where the primary aim is to minimise the risk of harm from ventilation and gas exchange that is no longer adequate. While numerous pharmacological interventions targeting the underlying pathophysiological mechanisms of ARDS have been tested in clinical trials, none of them have been shown to improve outcome, despite promising findings in preceding investigations in animals.

This review focuses on current challenges in the ventilatory support of patients with ARDS. In addition, it provides an overview of successful and unsuccessful pharmacological interventions for ARDS (table 1). Subsequent recommendations and suggestions for daily care of ARDS patients are given, in line with previous international recommendations $[1,2]$.

The article ends with a discussion on the challenges facing researchers when planning and performing clinical trials of ventilatory support or pharmacological interventions in patients with ARDS.

\section{Ventilatory support}

Ventilatory management of critically ill patients, including those with ARDS, has changed dramatically over the past three decades [3]. The paradigm of ventilation in critically ill patients has shifted from one that targeted physiological, and at times even supraphysiological goals to one that merely accepts the pathophysiology, at least to a certain level, and aims to prevent further harm [4]. Indeed, the targets have changed from completely reducing atelectases and aiming at normal to high arterial oxygen levels and strictly normal arterial $\mathrm{pH}$ or carbon dioxide levels, to tolerating atelectases and accepting low arterial oxygen levels and even hypercapnia when the price of full compensation of blood acidosis becomes too high. Treatment goals such as "permissive atelectasis", "permissive hypercapnia" and even "permissive hypoxaemia" have been introduced as targets of ventilatory support. Together with the increased knowledge and understanding of how mechanical ventilation can harm the lungs, major effort has been put into preventing or shortening the use of mechanical ventilation as much as possible, and using settings that are considered to be "lung protective".

\section{Noninvasive versus invasive mechanical ventilation in patients with ARDS}

The main advantages of noninvasive over invasive mechanical ventilatory support are the reduced need for sedation and prevention of ventilator-associated pneumonia. Noninvasive mechanical ventilation can be interrupted easily, and thus has the potential to shorten the time the lungs are subjected to the harmful effects of mechanical support.

While noninvasive mechanical ventilatory support by face mask was found to affect neither intubation rates nor clinical outcomes in a randomised controlled trial (RCT) of 123 ARDS patients [5], helmet ventilation was found to reduce the need for intubation when compared to oxygen therapy in a multicentre RCT of 81 ARDS patients [6], and to reduce intubation rates and even to improve survival when compared to a face mask in a single-centre randomised clinical trial of 83 ARDS patients [7].

TABLE 1 Ventilatory and pharmacological management of acute respiratory distress syndrome (ARDS) per responsive phenotype

\begin{tabular}{|c|c|c|}
\hline Intervention & Suggested/recommended & Responsive phenotype \\
\hline NIV & Recommended & $\begin{array}{l}\text { Early phase of respiratory failure, } \\
\text { with rapid response after start of NIV }\end{array}$ \\
\hline Tracheotomy & Suggested & Prolonged mechanical ventilation \\
\hline Low tidal volumes & Recommended & All patients with ARDS \\
\hline Plateau pressure $<30 \mathrm{cmH}_{2} \mathrm{O}$ & Recommended & All patients with ARDS \\
\hline Driving pressure $<15 \mathrm{cmH}_{2} \mathrm{O}$ & Suggested & All patients with ARDS \\
\hline High PEEP strategy & Recommended & $\mathrm{PaO}_{2} / \mathrm{FlO}_{2}<200$ \\
\hline Prone position & Recommended & $\mathrm{PaO}_{2} / \mathrm{FlO}_{2}<150$ \\
\hline Neuromuscular blocking agents & Recommended & $\mathrm{PaO}_{2} / \mathrm{FlO}_{2}<150$ and first $48 \mathrm{~h}$ of ARDS \\
\hline Extracorporeal membrane oxygenation & Suggested & Patients requiring rescue therapy \\
\hline Glucocorticosteroids & Suggested & No responsive phenotype identified \\
\hline
\end{tabular}

NIV: noninvasive ventilation; PEEP: positive end-expiratory pressure; $\mathrm{PaO}_{2}$ : arterial oxygen tension; $\mathrm{FlO}_{2}$ : inspiratory oxygen fraction. 
Oxygen administered through a high-flow nasal cannula is suggested to be an attractive strategy as a first-line therapy to avoid intubation, seen in the results of a multicentre RCT in which 301 hypoxaemic patients without hypercapnia received either high-flow oxygen therapy, standard oxygen therapy delivered through a face mask or noninvasive positive-pressure ventilation [8], but the beneficial effects found thus far need to be confirmed.

When noninvasive mechanical ventilatory support is used, patients should be monitored closely [9], as it can fail, for example because of patient nonacceptance and technical issues, but also when the disease progresses with a worsening of gas exchange. Substantial clinical (respiratory rate) and laboratory (blood gas analyses) improvements must be seen within the first few hours, otherwise it is necessary to proceed with invasive ventilation. A prospective observational trial of 101 patients suggested that a rapid shallow breathing index $>105$ breaths $\cdot \mathrm{min}^{-1} \cdot \mathrm{L}^{-1}[10]$ could be used to decide to intubate the patient. A prospective observational trial of 62 patients suggested that expired tidal volumes persistently $>9.5 \mathrm{~mL} \cdot \mathrm{kg}^{-1} \mathrm{predicted}$ body weight $(\mathrm{PBW})$ predicts noninvasive ventilation failure [11].

\section{Modes of invasive mechanical ventilatory support}

Volume-controlled modes of mechanical ventilation allow for better measurement of respiratory mechanics and driving pressures and may have a potential advantage with regard to the prevention of volutrauma. In addition, in contrast to pressure-controlled modes of mechanical ventilation, volume-controlled modes do guarantee a predefined tidal volume. Conversely, pressure-controlled modes have the alleged advantage of a decelerating flow curve during inspiration. Despite these potential physiological considerations, there are no outcome advantages of using a pressure-controlled mode over a volume-controlled mode, or vice versa. Indeed, one systematic review and meta-analysis of 34 studies did not suggest differences in any clinical outcome [12]. However, the studies were small and varied considerably in quality, and were at high risk of bias.

\section{Tracheotomy}

Tracheotomy may increase patient comfort. Several RCTs, including a large trial of 909 patients who did not necessarily have ARDS showed that early tracheostomy (within 4 days of admission to critical care) was not associated with an improvement in mortality or morbidity [13]. However, one systematic review and meta-analysis of 12 investigations suggested that early tracheotomy could lead to more ventilator-free days, shorter stays in intensive care, shorter duration of sedation and reduced long-term mortality [14]. The optimal timing of tracheotomy in critically ill patients remains a topic of debate. Presently, tracheotomy is recommended only when prolonged mechanical ventilation is expected.

\section{Tidal volume size and plateau pressure}

One key causal factor of so-called ventilator-induced lung injury is damage to the lungs due to overdistension from the use of high tidal volumes and inappropriately high airway pressures.

Mechanical ventilation targeting a tidal volume of $6 \mathrm{~mL} \cdot \mathrm{kg}^{-1} \mathrm{PBW}$ and plateau pressure $<30 \mathrm{cmH}_{2} \mathrm{O}$ was found to reduce mortality and morbidity in the pivotal ARDS Network "ARMA" trial of 861 ARDS patients [15]. One important notion is that tidal volume size should be titrated according to PBW (based on height and sex) and not to actual body weight, a frequently missed issue [16]. However, setting a low tidal volume could still result in overdistension and lung stress if the amount of aerated lung tissue is or remains low, as shown in an observational study in 30 patients [17]. In this elegant study, pulmonary computed tomography scanning at end-expiration showed that limiting tidal volume to $6 \mathrm{~mL} \cdot \mathrm{kg}^{-1} \mathrm{PBW}$ and plateau pressure to $30 \mathrm{cmH}_{2} \mathrm{O}$ may not be sufficient in patients characterised by large nonaerated parts. Either tidal volumes of $<6 \mathrm{~mL} \cdot \mathrm{kg}^{-1} \mathrm{PBW}$ [18] or higher positive end-expiratory pressures (PEEP) to recruit more lung tissue could be used [19]. Another approach is to adjust tidal volume to compliance by using the driving pressure (plateau pressure minus PEEP), aiming at a value $<15 \mathrm{cmH}_{2} \mathrm{O}$ [20]. Notice that this last approach is based on evidence coming from an individual patient data meta-analysis of RCTs that did not test the role of driving pressure. Direct RCT evidence for this approach is lacking.

PEEP

Three large RCTs comparing high with low PEEP in ARDS patients, the ALVEOLI trial in 549 ARDS patients [21], the LOVS trial in 983 ARDS patients [22] and the EXPRESS trial in 767 ARDS patients [23] showed that a ventilation strategy using a high PEEP does not reduce mortality, despite improved lung function. One meta-analysis using individual patient data from these three RCTs showed ventilation with high PEEP to be associated with better survival [24]. However, it should be acknowledged that the mortality benefit of high PEEP was restricted to patients with moderate or severe ARDS, and ventilation with high PEEP was associated with prolonged duration of ventilation in patients with mild ARDS. 
Ventilation with high PEEP balances between potential benefit (i.e. recruitment) and harm (i.e. overdistension), and individual responses to PEEP are very variable [25]. A test comparing several PEEP levels could help select the best PEEP level for an individual patient: PEEP titrations may be based on the extent of lung recruitability [26], changes in transpulmonary pressures [27] or more-easily captured changes in driving pressures [20].

\section{Rescue therapies}

Prone positioning results in redistribution of lung densities, with recruitment of the well perfused dorsal regions. Thus, prone positioning could result in a reduction in alveolar shunt and improved ventilationperfusion matching. While several RCTs of prone positioning in ARDS patients failed to show improvements in outcome, one systematic review and meta-analysis of nine RCTs showed an association between prone positioning and mortality, although only in patients with an arterial oxygen tension $\left(\mathrm{PaO}_{2}\right)$ / inspiratory oxygen fraction $\left(\mathrm{FIO}_{2}\right)$ ratio $<100$ [28]. One multicentre, prospective RCT in 466 ARDS patients with a $\mathrm{PaO}_{2} / \mathrm{FIO}_{2}<150, \mathrm{FIO}_{2} \geqslant 0.6$ and $\mathrm{PEEP} \geqslant 5 \mathrm{cmH}_{2} \mathrm{O}$ showed that early application of prolonged prone positioning sessions significantly decreased 28-day and 90-day mortality [29]. Of note, not all patients may benefit from prone positioning, but it should always be considered in the early phase of severe ARDS [29]. Relative contraindications for prone positioning include open abdominal wounds, unstable pelvic fractures, instable spinal lesions and brain injury and the absence of staff well-trained in prone positioning.

Muscle paralysis with neuromuscular blocking agents may avoid dyssynchrony, prevent excessive transpulmonary pressures and breath stacking by inspiratory efforts [30] and derecruitment by expiratory efforts [31]. Neuromuscular blocking agents have been shown to benefit patients with ARDS [32], confirmed in a meta-analysis of three RCTs [33]. Muscle paralysis with neuromuscular blocking agents should probably be reserved for patients with the most severe forms of ARDS, and restricted to the acute phase and during the first $48 \mathrm{~h}$.

Extracorporeal membrane oxygenation provides different degrees of carbon dioxide removal plus oxygenation, thus preventing in part harm caused by mechanical ventilatory support. This technique should only be used in the most severe cases of ARDS [34], and only by well-trained staff [35]. Extracorporeal carbon dioxide techniques have been used to allow mechanical ventilatory support at very low tidal volumes $\left(3-4 \mathrm{~mL} \cdot \mathrm{kg}^{-1} \mathrm{PBW}\right)[36,37]$. However, convincing evidence of the benefit of both techniques is absent and eagerly awaited. Trained staff and sufficient exposure could be critical for its safe use [35].

\section{Pharmacological interventions}

The initial or exudative phase of ARDS is characterised by a pro-inflammatory pulmonary response driven mainly by the innate immune system. The resulting unbalanced response leads to accumulation of protein-rich fluid in the alveolar space and the interstitium [38]. This process can be initiated by direct damage to the lung (e.g. pneumonia or aspiration) or as a consequence of endothelial damage and neutrophil activation (e.g. due to sepsis or blood transfusion). During the proliferative phase, repair mechanisms are activated in order to restore pulmonary function [39]. If repair is unsuccessful, for example due to continuing injury by mechanical ventilation or infection, lung tissue will become fibrotic. This phase in particular is associated with very high mortality rates [40].

Pharmacological interventions have mainly focused on dampening of the pro-inflammatory response in the initial phase of ARDS, reduction of pulmonary oedema or improvement of repair mechanisms. Besides treatment with glucocorticosteroids, none of the other pharmacological interventions tested so far in clinical trials showed a consistent reduction in morbidity and mortality [41].

\section{Glucocorticosteroids}

Glucocorticosteroids are effective in numerous inflammatory diseases across many fields in medicine. It seems plausible that high-dose glucocorticosteroids could improve outcomes in ARDS because of their pleiotropic anti-inflammatory action [42]. However, the evidence for benefit of glucocorticosteroids in ARDS is conflicting and the use of glucocorticosteroids in patients with ARDS remains controversial.

The latest individual data meta-analysis indicates an accelerated resolution of ARDS when patients are treated with a high dosage of glucocorticosteroids for a prolonged period of time [43]. Furthermore, methylprednisolone treatment has been found to be associated with shorter periods of need for invasive mechanical ventilation and lower mortality rates. Glucocorticosteroids have not been found to increase the risk of infections. These results are very encouraging, but should be seen in the light of the limitations of the original studies. There is clear need for additional clinical trials of glucocorticosteroids. 


\section{Salbutamol}

Salbutamol was suggested to reduce pulmonary oedema through stimulation of the sodium-potassium pump ( $\mathrm{Na} / \mathrm{K} / \mathrm{ATPase})$ but the largest trial to date was stopped after the inclusion of 326 patients because an interim analysis suggested that the intervention might cause harm [44].

\section{Surfactant}

Administration of exogenous surfactants was found to improve oxygenation when results of all studies were pooled in a systematic review, but did not influence mortality and should therefore not be used in patients with ARDS [45].

\section{$\mathrm{N}$-acetylcysteine}

$\mathrm{N}$-acetylcysteine is the best-studied antioxidant in ARDS. It increases glutathione levels and was thought to reduce the oxidative pulmonary damage seen in patients with ARDS. A systematic review of several smaller clinical trials in patients with ARDS showed that infusion of $\mathrm{N}$-acetylcysteine did not affect mortality [46].

\section{Neutrophil esterase inhibitor}

Neutrophil esterase seems to play a central role in the activation of neutrophils in the lung during the development of ARDS [47]. Sivelestat, a neutrophil esterase inhibitor, is used in the treatment of ARDS in Japan. However, pooled analysis of all available data showed no reduction in mortality, even when only studies performed in Japan were included [48].

\section{Granulocyte-macrophage colony-stimulating factor}

Granulocyte-macrophage colony-stimulating factor was tested as a treatment to promote resolution of lung injury, 3 days after patients fulfilled the ARDS criteria. A phase II study with 130 patients did not show any effect on length of stay or mortality [49].

\section{Challenges in research in patients with ARDS}

Many RCTs on mechanical ventilation and pharmacological treatment in ARDS have failed. Interestingly, all tested pharmacological interventions successfully passed preclinical studies in models of lung injury and even phase I/II clinical trials. These disappointing results contrast sharply with other fields of medicine, where up to one in every 10 drugs found to be beneficial and safe in preclinical investigations and phase I/II trials influence clinically relevant outcomes, are implemented in daily practice and included in recommendations in the guidelines [50]. Studies that show no benefit from the intervention could result from the selection of ineffective interventions and unresponsive patients for the intervention, as well as inadequate choices in trial design (for example, with regard to sample size and the end-points used [51]).

\section{Ineffective interventions}

Intervention efficacy is tested frequently in small-animal models for acute lung injury. Several factors, besides the fact that rodents may inherently respond differently to treatment, can prevent successful drug selection in preclinical studies.

Lung injury is experimentally evocated through "hits", which correspond to the many risk factors for ARDS (such as sepsis, trauma, pneumonia and aspiration). However, none of the small-animal models provide all the hallmarks of human $\operatorname{ARDS}[52,53]$ and therefore, by definition, fail to represent the clinical scenario of ARDS. Besides, most experiments use young male rodents that almost never have comorbidities for the evaluation of new treatments for ARDS, while patient populations seen in intensive care units are elderly and frequently have concomitant diseases such as diabetes mellitus, chronic obstructive pulmonary disease or active cancer [54]. The few studies that compared elderly rodents to younger ones indeed found a difference in the biological response between these groups $[55,56]$.

The timing of the start of treatment is another factor that may limit the translation of positive results from preclinical experiments to clinical trials in humans. Interventions may only be effective when given preventively or early in the course of disease; ARDS patients have to be recognised and informed consent must be obtained from the legal representative before a drug can be administrated in a clinical trial. Together, these factors may, at least in part, explain the failed translation of preclinical results and we should put more effort in creating models that better reflect the clinical situation.

\section{Balance between benefit and harm}

A second challenge in clinical trials of ARDS treatments is the inherent biological heterogeneity. The biological heterogeneity directly relates to the ARDS definition, which is based on clinical criteria without a central, singular underlying pathophysiological mechanism [57]. A drug targeting a specific molecular 
mechanism that is effective in part of the population might harm patients with a separate biological response. Therefore, the outcome of the study is highly dependent on the prevalence of patients that are responsive (e.g. in whom benefit outweighs harm) to the treatment in the included population. It is the premise of precision medicine to enrich this group as much as possible with patients with a responsive phenotype (also called predictive enrichment) [58]. The selection of the right patient for the right treatment is one the largest challenges for the coming decade $[59,60]$.

\section{Exclusion of patients with a negative balance between benefit and harm}

Patients with a particular phenotype that is responsive to a treatment can be identified through pathophysiological reasoning. An illustrative example is the application of prone positioning in patients with a $\mathrm{PaO}_{2} / \mathrm{FIO}_{2}$ ratio $<150$ [61]. The physiological consequences of laying a patient in prone position include the recruitment of the dorsal parts of the lungs and derecruitment of the ventral parts of the lung $[62,63]$. Because of the ventro-dorsal asymmetry of the thorax, prone positioning a patient with ARDS frequently results in an overall recruitment effect [63]. These phenomena can be utilised in patients with ARDS (see the section on mechanical ventilation) because it will improve gas exchange and reduce ventilator-induced lung injury [62]. However, this procedure is not without complications such as hypotension, pressure sores, accidental extubation and the complications of more sedation [64]. With the background knowledge that patients with lower $\mathrm{PaO}_{2} / \mathrm{FIO}_{2}$ scores have an increased heterogeneity of ventilation in the lung and the most problems with gas exchange, this is the phenotype that is most likely to benefit from the intervention.

If we apply this reasoning to pharmacological interventions, we could aim to identify key mediators in the pathophysiology of ARDS and design drugs to target these mediators. Studies can be enriched through the selection of patients that have a higher expression of the targeted molecules. For example, a study investigating an antibody against interleukin-8 could choose to select patients based on high level of interleukin-8 in plasma, or, even better, locally in the lung. Patient selection based on the treatment mechanism is still not utilised sufficiently in intensive care medicine research and may improve the chances on finding effective pharmacological interventions for ARDS.

\section{Better selection of phenotypes through an unbiased, data-driven approach}

A second approach towards the definition of ARDS phenotypes is an unbiased, data-driven analysis of clinical or biological data. Although the case for the application of prone positioning in a patients with a clinical phenotype of a low $\mathrm{PaO}_{2} / \mathrm{FIO}_{2}$ ratio seems logical with hindsight, almost all studies were designed to include all patients with ARDS. The low $\mathrm{PaO}_{2} / \mathrm{FIO}_{2}$ ratio phenotype was recognised only after several RCTs were completed [28].

In essence, the data-driven approach recognises that we are inherently biased in our recognition of subgroups and it faces the problem of phenotype selection from the other direction, not initiated by pathophysiology, but by empirical evidence, which is later translated back to pathophysiology.

If we recognise the complexity of the biological processes that contribute to ARDS it seems overly simplistic and therefore unlikely that we would identify a single marker such as $\mathrm{PaO}_{2} / \mathrm{FIO}_{2}$ ratio that is predictive of a specific, responsive phenotype. Over the past decades, vast improvements in bioanalytical assays and computing power have introduced the age of "omics" analyses. When more than one variable is considered to define a phenotype, a data-driven approach is even more warranted. Computer algorithms have no inherent struggles with highly dimensional datasets and we can utilise that capacity to reduce complex datasets to understandable proportions. The output of computer algorithms can serve as inputs
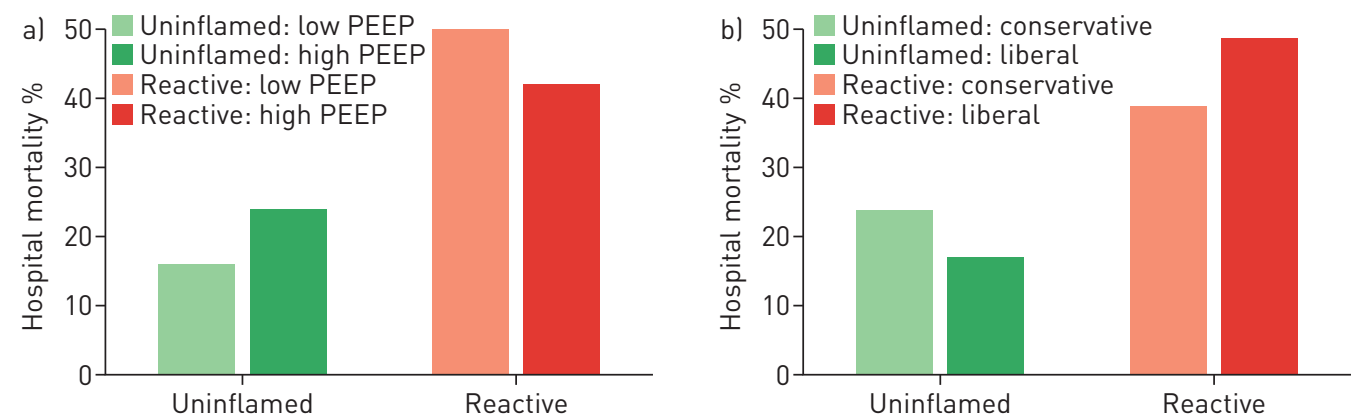

FIGURE 1 Differential response to treatment between two phenotypes of acute respiratory distress syndrome. a) High and low positive end-expiratory pressure (PEEP); b) conservative and liberal fluid management. 
for clinicians and can guide them in making the right clinical decision. With unbiased cluster analysis, one of the most widely used algorithms for identifying patterns, researchers can identify patients who show similar biological "fingerprints", even though they might not look alike from a clinical perspective. This data-driven analysis limits the danger of self-fulfilling prophecies based on widely accepted paradigms and are hypothesis-generating.

Two landmark articles suggest that ARDS can be separated into at least two distinct phenotypes based on unbiased, data-driven analyses of clinical data and several plasma biomarkers of inflammation, coagulation and endothelial activation $[65,66]$. One phenotype is characterised by a hyperinflammatory and hypercoagulatory state in the blood, while the other phenotype shows a hypo-inflammatory state and high bicarbonate levels $[65,66]$. One of the major disadvantages of such a data-driven approach is the danger of over-fitting to the specific dataset. Importantly, very similar phenotypes were found independently in a group of ARDS patients that was separated in time and place, and analysed using an alternative approach [67]. Progress in the identification of specific phenotypes is not only seen in ARDS, but also in other problems frequently encountered in the intensive care unit, such as sepsis and failure to wean $[68-70]$.

\section{Implications for clinical practice in the future}

Post hoc analysis of two multicentre RCTs indicate that the two above-described phenotypes show a differential response to a high (versus conventional) PEEP strategy and a conservative (versus liberal) fluid management. Fluid management was steered by a strict protocol relying on the central venous pressure or pulmonary artery occlusion pressure, need for vasopressors and an "effective circulation" (combination of cardiac index and physical examination) [71] resulting in the advice for vasopressor use, furosemide administration or fluid administration. The hyper-inflammatory phenotype seemed to benefit from a higher PEEP strategy and conservative fluid management, while the hypo-inflammatory phenotype did not seem to benefit and might even be harmed by the intervention (figure 1). Of course, post hoc analyses of RCTs do not provide definitive answers, as research questions are not stated beforehand and the randomisation process is disturbed, but it indicates that our simplistic views on the management of ARDS may need to be revised in the near future.

\section{Conclusions}

There are several ventilation-related interventions that have a strong potential to improve outcomes of patients with ARDS. Of all tested pharmacological interventions, only treatment with glucocorticosteroids may impact outcomes in these patients. We are in need of better-designed RCTs, not necessarily larger trials in the field of ARDS. We advocate a personalised approach to the treatment of ARDS patients, with the recognition of individual phenotypes to guide treatment decisions. The challenge in research is the identification of phenotypes of ARDS that benefit from specific treatments. Phenotypes might be defined based on clinical parameters (such as $\mathrm{PaO}_{2} / \mathrm{FIO}_{2}$ ratio) or based on profiles of biological markers.

\section{References}

1 Rhodes A, Evans LE, Alhazzani W, et al. Surviving sepsis campaign: international guidelines for management of sepsis and septic shock: 2016. Intensive Care Med 2017; 43: 304-377.

2 Chiumello D, Brochard L, Marini JJ, et al. Respiratory support in patients with acute respiratory distress syndrome: an expert opinion. Crit Care 2017; 21: 240.

3 Martin-Loeches I, Levy MM, Artigas A. Management of severe sepsis: advances, challenges, and current status. Drug Des Devel Ther 2015; 9: 2079-2088.

4 Martin-Loeches I, Perner A. Focus on infection and sepsis in intensive care patients. Intensive Care Med 2016; 42: 491-493.

5 Delclaux C, L'Her E, Alberti C, et al. Treatment of acute hypoxemic nonhypercapnic respiratory insufficiency with continuous positive airway pressure delivered by a face mask: a randomized controlled trial. JAMA 2000; 284: 2352-2360.

6 Brambilla AM, Aliberti S, Prina E, et al. Helmet CPAP vs. oxygen therapy in severe hypoxemic respiratory failure due to pneumonia. Intensive Care Med 2014; 40: 942-949.

7 Patel BK, Wolfe KS, Pohlman AS, et al. Effect of noninvasive ventilation delivered by helmet $v s$ face mask on the rate of endotracheal intubation in patients with acute respiratory distress syndrome: a randomized clinical trial. JAMA 2016; 315: 2435-2441.

8 Frat J-P, Thille AW, Mercat A, et al. High-flow oxygen through nasal cannula in acute hypoxemic respiratory failure. N Engl J Med 2015; 372: 2185-2196.

9 Agarwal R, Aggarwal AN, Gupta D. Role of noninvasive ventilation in acute lung injury/acute respiratory distress syndrome: a proportion meta-analysis. Respir Care 2010; 55: 1653-1660.

10 Berg KM, Lang GR, Salciccioli JD, et al. The rapid shallow breathing index as a predictor of failure of noninvasive ventilation for patients with acute respiratory failure. Respir Care 2012; 57: 1548-1554.

11 Carteaux G, Millán-Guilarte T, De Prost N, et al. Failure of noninvasive ventilation for de novo acute hypoxemic respiratory failure: role of tidal volume. Crit Care Med 2016; 44: 282-290.

12 Rittayamai N, Katsios CM, Beloncle F, et al. Pressure-controlled vs volume-controlled ventilation in acute respiratory failure: a physiology-based narrative and systematic review. Chest 2015; 148: 340-355. 
13 Young D, Harrison DA, Cuthbertson $\mathrm{BH}$, et al. Effect of early vs late tracheostomy placement on survival in patients receiving mechanical ventilation: the TracMan randomized trial. JAMA 2013; 309: 2121-2129.

14 Hosokawa K, Nishimura M, Egi M, et al. Timing of tracheotomy in ICU patients: a systematic review of randomized controlled trials. Crit Care 2015; 19: 424.

15 ARDS-Network. Ventilation with lower tidal volumes as compared with traditional tidal volumes for acute lung injury and the acute respiratory distress syndrome. N Engl J Med 2000; 342: 1301-1308.

16 Wolthuis EK, Korevaar JC, Spronk P, et al. Feedback and education improve physician compliance in use of lung-protective mechanical ventilation. Intensive Care Med 2005; 31: 540-546.

17 Terragni PP, Rosboch G, Tealdi A, et al. Tidal hyperinflation during low tidal volume ventilation in acute respiratory distress syndrome. Am J Respir Crit Care Med 2007; 175: 160-166.

18 Retamal J, Libuy J, Jiménez $\mathrm{M}$, et al. Preliminary study of ventilation with $4 \mathrm{ml} / \mathrm{kg}$ tidal volume in acute respiratory distress syndrome: feasibility and effects on cyclic recruitment - derecruitment and hyperinflation. Crit Care 2013; 17: R16.

19 Putensen C, Theuerkauf N, Zinserling J, et al. Meta-analysis: ventilation strategies and outcomes of the acute respiratory distress syndrome and acute lung injury. Ann Intern Med 2009; 151: 566-576.

20 Amato MBP, Meade MO, Slutsky AS, et al. Driving pressure and survival in the acute respiratory distress syndrome. N Engl J Med 2015; 372: 747-755.

21 Brower RG, Lanken PN, MacIntyre N, et al. Higher versus lower positive end-expiratory pressures in patients with the acute respiratory distress syndrome. N Engl J Med 2004; 351: 327-336.

22 Meade MO, Cook DJ, Guyatt GH, et al. Ventilation strategy using low tidal volumes, recruitment maneuvers, and high positive end-expiratory pressure for acute lung injury and acute respiratory distress syndrome. JAMA 2008; 299: 637-645.

23 Mercat A, Richard J-C, Vielle B, et al. Positive end-expiratory pressure setting in adults with acute lung injury and acute respiratory distress syndrome: a randomized controlled trial. JAMA 2008; 299: 646-655.

24 Briel M, Meade M, Mercat A, et al. Higher vs lower positive end-expiratory pressure in patients with acute lung injury and acute respiratory distress syndrome: systematic review and meta-analysis. JAMA 2010; 303: 865-873.

25 Goligher EC, Kavanagh BP, Rubenfeld GD, et al. Oxygenation response to positive end-expiratory pressure predicts mortality in acute respiratory distress syndrome. A secondary analysis of the LOVS and ExPress trials. Am J Respir Crit Care Med 2014; 190: 70-76.

26 Kacmarek RM, Villar J, Sulemanji D, et al. Open lung approach for the acute respiratory distress syndrome: a pilot, randomized controlled trial. Crit Care Med 2016; 44: 32-42.

27 Talmor D, Sarge T, Malhotra A, et al. Mechanical ventilation guided by esophageal pressure in acute lung injury. N Engl J Med 2008; 359: 2095-2104.

28 Sud S, Friedrich JO, Taccone P, et al. Prone ventilation reduces mortality in patients with acute respiratory failure and severe hypoxemia: systematic review and meta-analysis. Intensive Care Med 2010; 36: 585-599.

29 Guérin C, Reignier J, Richard J-C, et al. Prone positioning in severe acute respiratory distress syndrome. $\mathrm{N}$ Engl $\mathrm{J}$ Med 2013; 368: 2159-2168.

30 Beitler JR, Sands SA, Loring SH, et al. Quantifying unintended exposure to high tidal volumes from breath stacking dyssynchrony in ARDS: the BREATHE criteria. Intensive Care Med 2016; 42: 1427-1436.

31 Guervilly C, Bisbal M, Forel JM, et al. Effects of neuromuscular blockers on transpulmonary pressures in moderate to severe acute respiratory distress syndrome. Intensive Care Med 2017; 43: 408-418.

32 Papazian L, Forel JM, Gacouin A, et al. Neuromuscular blockers in early acute respiratory distress syndrome. N Engl J Med 2010; 363: 1107-1116.

33 Neto AS, Pereira M, Espósito DC, et al. Neuromuscular blocking agents in patients with acute respiratory distress syndrome: a summary of the current evidence from three randomized controlled trials. Ann Intensive Care 2012; 2: 33 .

34 Ventetuolo CE, Muratore CS. Extracorporeal life support in critically ill adults. Am J Respir Crit Care Med 2014; 190: 497-508.

35 Peek GJ, Mugford M, Tiruvoipati R, et al. Efficacy and economic assessment of conventional ventilatory support versus extracorporeal membrane oxygenation for severe adult respiratory failure (CESAR): a multicentre randomised controlled trial. Lancet 2009; 374: 1351-1363.

36 Marhong JD, Munshi L, Detsky M, et al. Mechanical ventilation during extracorporeal life support (ECLS): a systematic review. Intensive Care Med 2015; 41: 994-1003.

37 Fanelli V, Ranieri M V, Mancebo J, et al. Feasibility and safety of low-flow extracorporeal carbon dioxide removal to facilitate ultra-protective ventilation in patients with moderate acute respiratory distress syndrome. Crit Care 2016; 20: 36 .

38 Thompson B, Chambers R, Liu K. Acute respiratory distress syndrome. N Engl J Med 2017; 377: 562-572.

39 González-López A, Astudillo A, García-Prieto E, et al. Inflammation and matrix remodeling during repair of ventilator-induced lung injury. Am J Physiol Lung Cell Mol Physiol 2011; 301: L500-L509.

40 Lorente JA, Ballén-Barragán A, Herrero R, et al. Acute respiratory distress syndrome: does histology matter? Crit Care 2015; 19: 337.

41 Boyle AJ, McNamee JJ, McAuley DF. Biological therapies in the acute respiratory distress syndrome. Expert Opin Biol Ther 2014; 14: 969-981

42 Cain DW, Cidlowski JA. Immune regulation by glucocorticoids. Nat Rev Immunol 2017; 17: $233-247$.

43 Meduri GU, Bridges L, Shih M-C, et al. Prolonged glucocorticoid treatment is associated with improved ARDS outcomes: analysis of individual patients' data from four randomized trials and trial-level meta-analysis of the updated literature. Intensive Care Med 2016; 42: 829-840.

44 Smith FG, Perkins GD, Gates S, et al. Effect of intravenous $\beta-2$ agonist treatment on clinical outcomes in acute respiratory distress syndrome (BALTI-2): a multicentre, randomised controlled trial. Lancet 2012; 379: 229 -235.

45 Davidson WJ, Dorscheid D, Spragg R, et al. Exogenous pulmonary surfactant for the treatment of adult patients with acute respiratory distress syndrome: results of a meta-analysis. Crit Care 2006; 10: R41.

46 Zhang Y, Ding S, Li C, et al. Effects of $\mathrm{N}$-acetylcysteine treatment in acute respiratory distress syndrome: a meta-analysis. Exp Ther Med 2017; 14: 2863-2868.

47 Grommes J, Soehnlein O. Contribution of neutrophils to acute lung injury. Mol Med 2011; 17: $293-307$. 

lung injury (ALI) and acute respiratory distress syndrome (ARDS): a systematic review and meta-analysis. Intern Med 2010; 49: 2423-2432.

49 Paine R, Standiford TJ, Dechert RE, et al. A randomized trial of recombinant human granulocyte-macrophage colony stimulating factor for patients with acute lung injury. Crit Care Med 2012; 40: 90-97.

50 Thomas DW, Burns J, Audette J, et al. Clinical Development Success Rates 2006-2015. BIO Industry Analysis. https://www.bio.org/sites/default/files/Clinical\%20Development\%20Success\%20Rates\%202006-2015\%20-\%20BIO,\% 20Biomedtracker,\%20Amplion\%202016.pdf Biotechnology Innovation Organization (BIO), 2016.

51 Gattinoni L, Giomarelli P. Acquiring knowledge in intensive care: merits and pitfalls of randomized controlled trials. Intensive Care Med 2015; 41: 1460-1464.

52 Matute-Bello G, Frevert CW, Martin TR. Animal models of acute lung injury. Am J Physiol Lung Cell Mol Physiol 2008; 295: L379-L399.

53 Matute-Bello G, Downey G, Moore BB, et al. An official American Thoracic Society workshop report: features and measurements of experimental acute lung injury in animals. Am J Respir Cell Mol Biol 2011; 44: 725-738.

54 Bellani G, Laffey JG, Pham T, et al. Epidemiology, patterns of care, and mortality for patients with acute respiratory distress syndrome in intensive care units in 50 countries. JAMA 2016; 315: 788-800.

55 Schouten LRA, Helmerhorst HJF, Wagenaar GTM, et al. Age-dependent changes in the pulmonary renin-angiotensin system are associated with severity of lung injury in a model of acute lung injury in rats. Crit Care Med 2016; 44: e1226-e1235.

56 Schouten LRA, Schultz MJ, van Kaam AH, et al. Association between maturation and aging and pulmonary responses in animal models of lung injury: a systematic review. Anesthesiology 2015; 123: 389-408.

57 Agrawal A, Zhuo H, Brady S, et al. Pathogenetic and predictive value of biomarkers in patients with ALI and lower severity of illness: results from two clinical trials. Am J Physiol Lung Cell Mol Physiol 2012; 303: L634-L639.

58 Prescott AHC, Calfee CS, Taylor B, et al. Towards smarter lumping and smarter splitting: rethinking strategies for sepsis and acute respiratory distress syndrome clinical trial design. Am J Respir Crit Care Med 2016; 194: 147-155.

59 Auffray C, Adcock IM, Chung KF, et al. An integrative systems biology approach to understanding pulmonary diseases. Chest 2010; 137: 1410-1416.

60 Shankar-Hari M, McAuley DF. Divide and conquer: identifying acute respiratory distress syndrome subphenotypes. Thorax 2017; 72: 867-869.

$61 \mathrm{Hu}$ SL, He HL, Pan C, et al. The effect of prone positioning on mortality in patients with acute respiratory distress syndrome: a meta-analysis of randomized controlled trials. Crit Care 2014; 18: R109.

62 Guérin C. Prone ventilation in acute respiratory distress syndrome. Eur Respir Rev 2014; 23: 249-257.

63 Gattinoni L, Taccone P, Carlesso E, et al. Prone position in acute respiratory distress syndrome. Rationale, indications, and limits. Am J Respir Crit Care Med 2013; 188: 1286-1293.

64 Park SY, Kim HJ, Yoo KH, et al. The efficacy and safety of prone positioning in adults patients with acute respiratory distress syndrome: a meta-analysis of randomized controlled trials. J Thorac Dis 2015; 7: 356-367.

65 Calfee CS, Delucchi K, Parsons PE, et al. Subphenotypes in acute respiratory distress syndrome: latent class analysis of data from two randomised controlled trials. Lancet Respir Med 2014; 2: 611-620.

66 Famous KR, Delucchi K, Ware LB, et al. Acute respiratory distress syndrome subphenotypes respond differently to randomized fluid management strategy. Am J Respir Crit Care Med 2017; 195: 331-338.

67 Bos LD, Schouten LR, van Vught LA, et al. Identification and validation of distinct biological phenotypes in patients with acute respiratory distress syndrome by cluster analysis. Thorax 2017; 72: 876-883.

68 Scicluna BP, van Vught LA, Zwinderman AH, et al. Classification of patients with sepsis according to blood genomic endotype: a prospective cohort study. Lancet Respir Med 2017; 5: 816-826.

69 Silva S, Ait Aissa D, Cocquet P, et al. Combined thoracic ultrasound assessment during a successful weaning trial predicts postextubation distress. Anesthesiology 2017; 127: 666-674.

70 Davenport EE, Burnham KL, Radhakrishnan J, et al. Genomic landscape of the individual host response and outcomes in sepsis: a prospective cohort study. Lancet Respir Med 2016; 4: 259-271.

71 The National Heart, Lung, and Blood Institute Acute Respiratory Distress Syndrome (ARDS) Clinical Trials Network. Comparison of two fluid-management strategies in acute lung injury. N Engl J Med 2006; 354: 2564-2575. 